\title{
Ectopic Solitary Cortical Anaplastic Ependymoma in a Child: A Rare Entity with Short Illustrative Review
}

\author{
Sachin Guthe ${ }^{1}$ Pravin Survashe ${ }^{1}$ Vernon Velho ${ }^{1}$ Laxmikant Bhopale ${ }^{1}$ Poonam Darade ${ }^{2}$ \\ ${ }^{1}$ Department of Neurosurgery, Grant Medical College and Sir J.J. \\ Group of Hospitals, Mumbai, Maharashtra, India \\ 2Department of Radiology, Grant Medical College and Sir J.J. Group \\ of Hospitals Mumbai, Maharashtra, India \\ Address for correspondence Dr. Sachin Guthe, MCh Neurosurgery, \\ Department of Neurosurgery, 4th Floor, Main Building, J.J. \\ Hospital Campus, Byculla, Mumbai, Maharashtra 400 008, India \\ (e-mail: spguthe@gmail.com).
}

Indian J Neurotrauma 2018;7:249-252
Abstract
Keywords
- anaplastic
- cortical
- pediatric
ependymoma

Ependymomas are usually infratentorial and intraventricular. They originate from the ependymal cell lining of the ventricles. Cortical extraventricular supratentorial ependymomas are rare and fewer than 15 cases are reported worldwide. In pediatric age group, seven cases are reported. We report a rare case of 4-year-old boy with right frontoparietal anaplastic ependymoma who underwent gross total excision of lesion.

\section{Introduction}

Ependymomas are tumors derived from ependymal cells lining the ventricles or from the central canal of the spinal cord. It represents 3 to $9 \%$ of all neuroepithelial neoplasms, 6 to $12 \%$ of all pediatric brain tumors, and almost one-third of all brain tumors in patients younger than 3 years. Approximately $40 \%$ of ependymomas are supratentorial, whereas $60 \%$ are infratentorial in location. Ependymomas may manifest at any age (documented age ranges from 1 month to 81 years) with no sex predilection. Posterior fossa ependymomas are common in children (mean age: 6 years) and supratentorial ependymoma generally manifests in an older age group (mean age: 18-24 years). Although the lesion arises from the ventricular system, it can grow beyond the ventricles, through the cerebral tissue, representing the extraventricular form. It can exist in extraventricular structures, without any connection to ventricular system, representing the rare group of ectopic ependymoma. In the literature not more than 30 cases have been reported, of which 15 were diagnosed purely cortical and only 7 cases were anaplastic (grade III) lesions - Table $1{ }^{1}$ We report a rare case of solitary cortical pediatric anaplastic ependymoma.

\section{Illustrative Case}

A 4-year-old boy presented with progressively increasing headache and vomiting of 1-month duration. On examination he was drowsy and had left hemiparesis. A contrastenhanced computed tomographic (CT) scan of the brain showed a right frontal superficially located mixed-density lesion with heterogeneous enhancement (-Fig. 1). Intraoperatively gross total excision of the tumor was done via

Table 1 All reported cases of pure cortical supratentorial grade III ependymomas

\begin{tabular}{|l|l|l|}
\hline Series & Cases & Grade \\
\hline Davis et $\mathrm{al}^{2}$ & 1 & III \\
\hline${\text { Alexiou et } \mathrm{al}^{3}}^{3}$ & 1 & $\mathrm{III}$ \\
\hline${\text { Hamano et } \mathrm{al}^{4}}^{4}$ & 1 & $\mathrm{III}$ \\
\hline${\text { Akyuz et } \mathrm{al}^{5}}^{1}$ & 1 & $\mathrm{III}$ \\
\hline Romero et al $^{1}$ & 1 & $\mathrm{III}$ \\
\hline${\text { Kharosekar et } \mathrm{al}^{6}}^{6}$ & 1 & $\mathrm{III}$ \\
\hline Present study & 1 & $\mathrm{III}$ \\
\hline
\end{tabular}

\section{received}

July 24, 2016

accepted after revision

January 23, 2017

published online

November 3, 2017
DOI https://doi.org/

10.1055/s-0037-1601360.

ISSN 2277-954X.

\section{C2018 Neurological Surgeons'}

Society of India
License terms

() (1) $\odot \circledast$ 


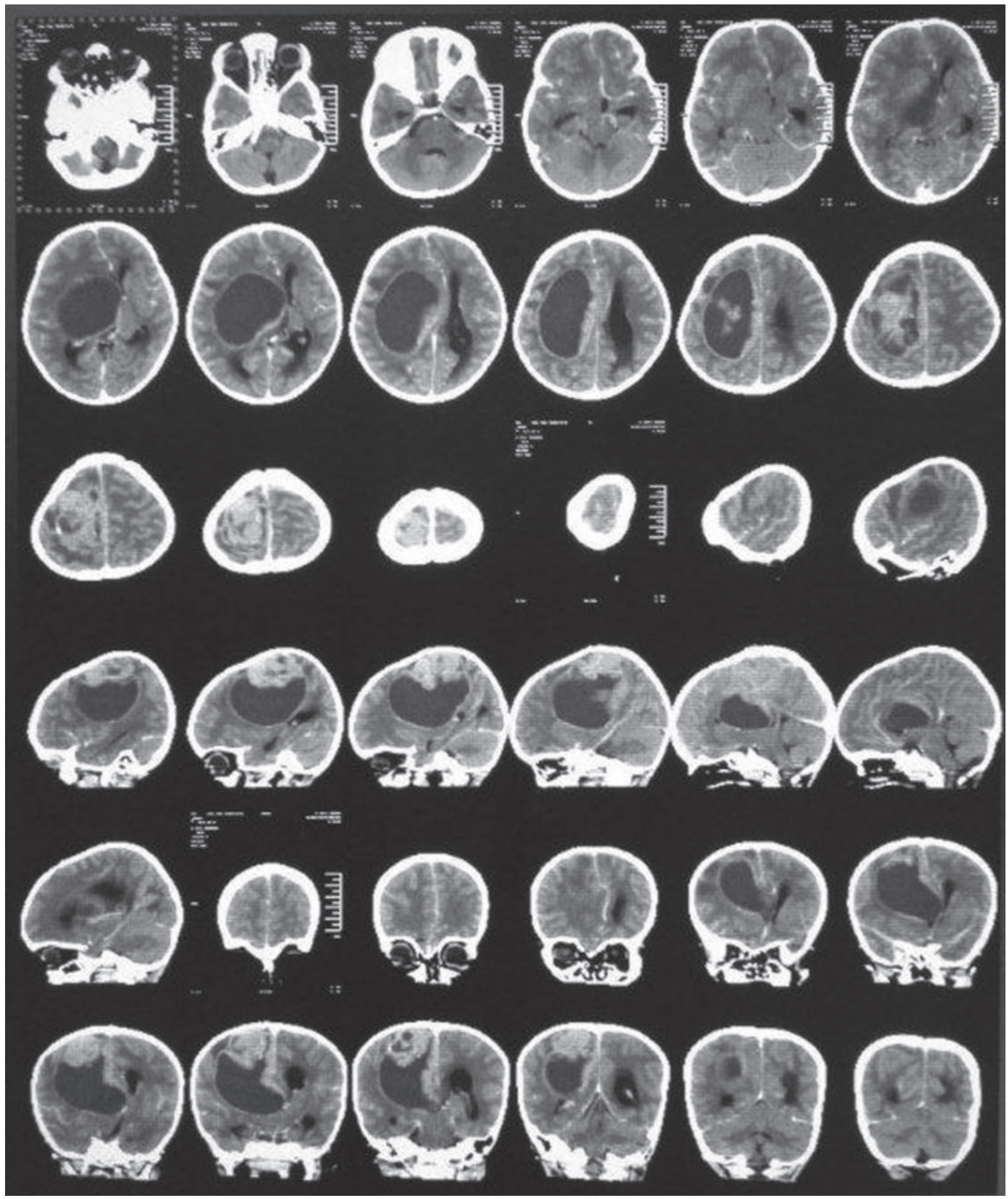

Fig. 1 Preoperative CT scan of the brain. CT, computed tomography.

right frontoparietal craniectomy (-Fig. 2). No connection of tumor to the ventricular ependymal lining was noted. Tumor was moderately vascular and suckable. Margins were well defined. The postoperative period was uneventful. He made a good recovery and there was no fresh neurologic deficit. Histopathology examination showed plump spindle-shaped ependymal cells. The cells showed a tendency to form rosettes. There were pseudorosettes around blood vessels. Frequent mitosis, foci of microvascular proliferation, and large confluent areas of necrosis were seen. There were foci of dystrophic calcification (-Fig. 3). Immunohistochemistry was positive for glial fibrillary acidic protein and epithelial membrane antigen. Ki67 proliferation index was greater than $15 \%$ suggestive of anaplastic cortical ependymoma grade III.

\section{Discussion}

Although approximately half of the supratentorial ependymomas arise from the wall of third or lateral ventricles 


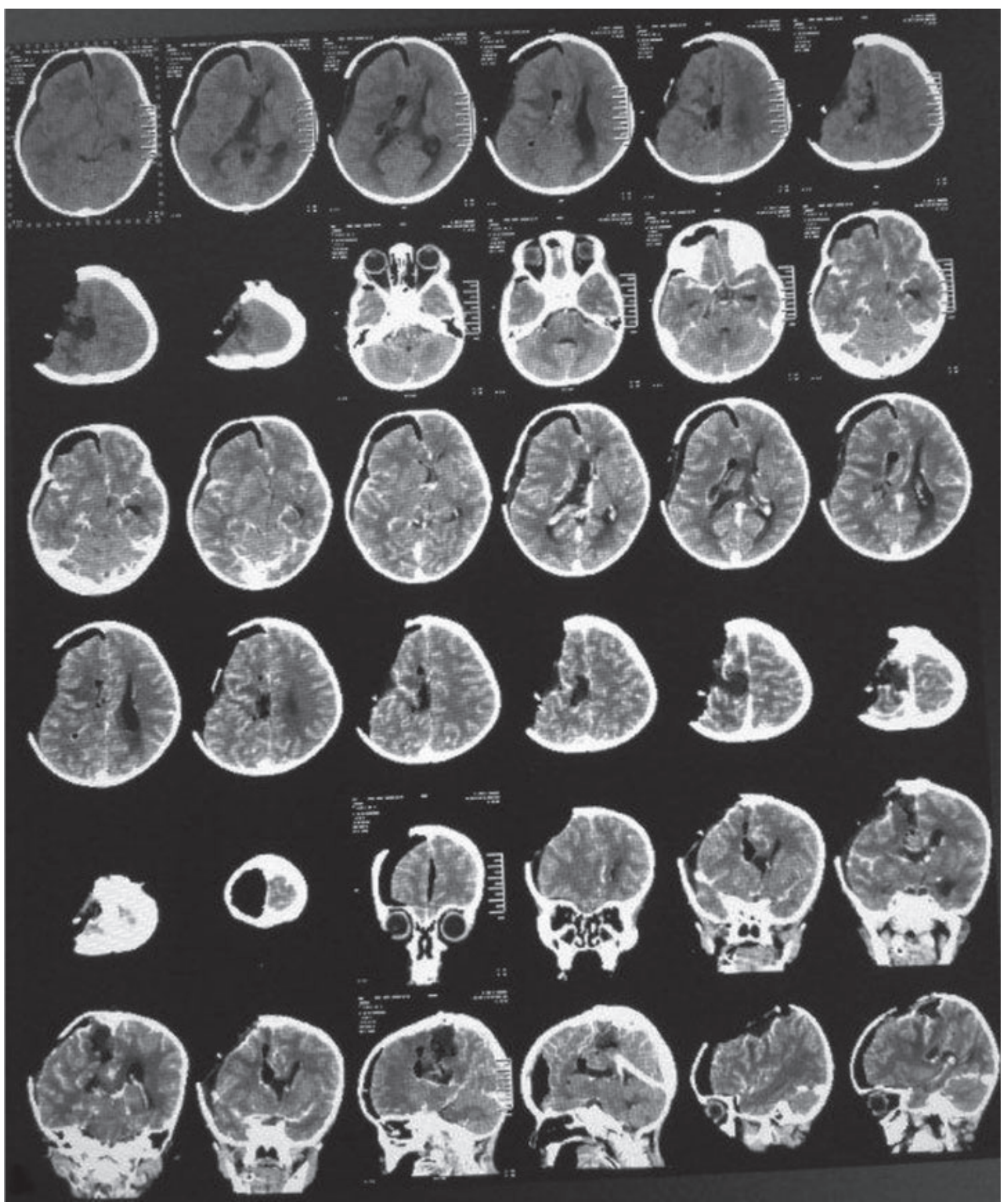

Fig. 2 Immediate postoperative CT of the brain showing gross total excision of tumor. CT, computed tomography.

and are purely intraventricular, few may extend through adjacent cerebral tissue, representing extraventricular forms of ependymoma. Only few cases occur in distant places of the ventricular system, representing rare cases of ectopic lesions. It is speculated that ectopic ependymomas may arise from embryonic rests of ependymal tissue trapped in the developing cerebral hemispheres. Supratentorial ependymoma grows into third or lateral ventricle; it is predominant involving the brain parenchyma at the diagnosis. Hamano et al reported that $83 \%$ of supratentorial ependymomas are in the cerebral parenchyma. Owing to its parenchymal location, the supratentorial ependymoma tends to be larger in size at the diagnosis.

Roncaroli et al found that $94 \%$ of supratentorial tumors manifest with a size larger than $4 \mathrm{~cm}$ and often contain a cystic component. Despite their large size in the cerebral hemispheres, symptoms are relatively mild until a later stage of presentation. Symptoms of raised intracranial pressure such as headache and vomiting are common, whereas focal signs as limb weakness and seizures are less prevalent. The principal differential diagnosis of extraventricular supratentorial ependymoma must include astrocytoma (both low-grade and 


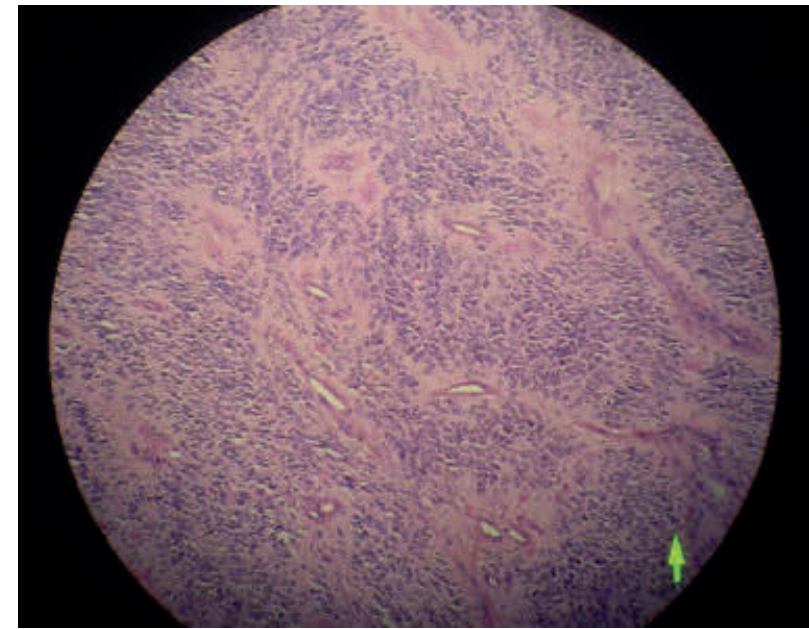

Fig. 3 Histopathology image showing perivascular pseudorosettes.

glioblastoma multiforme), supratentorial primitive neuroectodermal tumor (PNET), ganglioglioma, gangliocytoma, and oligodendroglioma. They have no typical imaging features or findings; hence every lesion, with extension to the ventricular system, should make us suspicious of this fact. They are iso- to hypodense attenuations to surrounding normal brain tissue at nonenhanced CT. They are iso- to hypointense attenuations relative to normal white matter on nonenhanced T1-weighted magnetic resonance (MR) images and hyperintense attenuations on T2- and proton-density-weighted MR images. Foci of signal heterogeneity within a solid neoplasm represent methemoglobin, hemosiderin, necrosis, or calcification, which is very common in this tumor (40-80\% of cases). Ependymomas can display variable contrast enhancement behavior but generally enhance moderately intensely at both $\mathrm{CT}$ and magnetic resonance imaging (MRI), with central areas of necrosis. ${ }^{1}$

Histologically, the tumor cells are characteristically organized in perivascular pseudorosettes and, less commonly, ependymal rosettes. Although ependymomas are moderately cellular tumors with rare mitotic figures (World Health Organization [WHO] grade II lesions), our patient had a more aggressive tumor, classified as WHO grade III. Fewer than five ectopic anaplastic ependymomas were reported previously.

The best treatment is radical resection, because it appears that tumor resectability is the most important factor associated with recurrence. Solitary cortical (ectopic) tumors are comparatively easier to approach than lesions with connection to ventricles, having better outcome. Postoperative radiotherapy should be administered in every case of partially resected ependymomas or anaplastic tumors. At present chemotherapy and prophylactic cranio-spinal irradiation are not indicated as adjuvant treatment.

Age at presentation is also a significant prognostic factor. Patients younger than 3 years have a significantly worse outcome than older children or adults. The last prognostic variable is the duration of symptoms before diagnosis. Patients with symptoms before diagnosis less than 1 month have a worse outcome than those with a more protracted course.
Prognostic factors of ependymomas that positively contribute to progression-free survival and longer survival are still elusive, even in histologic characteristics. The 5-year progression-free survival rate for children overall is approximately $50 \%$ and 10 -year survival rates for adults are $57.1 \%$ and $45 \%$, respectively. Only total tumor resection is considered as a reliable prognostic factor for predicting longer survival time. Of patients with no radiologic evidence of residual tumor, $75 \% \pm 15 \%$ will remain tumor free after 5 years as opposed to the group of patients with residual disease in which progression cannot be stopped.

An increased risk of recurrence was reported with a high histologic grade, incomplete resection, and a Karnofsky performance status that is 80 or less. ${ }^{7,8}$

Our patient was treated with radical surgery and subjected to postoperative radiotherapy, due to anaplastic grade of tumor. There was no evidence of gross residual tumor at postoperative imaging. The patient had a good recovery of neurologic symptoms. His left hemiparesis improved. Now he is regularly being followed in our outpatient clinic.

\section{Consent}

Written informed consent was obtained from the patient for publication of this case report and accompanying images.

\section{Funding}

None.

\section{Conflict of Interest}

None.

\section{References}

1 Romero FR, Zanini MA, Ducati LG, Vital RB, de Lima Neto NM, Gabarra RC. Purely cortical anaplastic ependymoma. Case Rep Oncol Med 2012;2012:1-4

2 Davis MJ, Hasan F, Weinreb I, Wallace MC, Kiehl TR. Extraventricular anaplastic ependymoma with metastasis to scalp and neck. Journal of neuro-oncology 2011 Sep 1; 104(02):599-604

3 Alexiou GA, Panagopoulos D, Moschovi M, Stefanaki K, Sfakianos G, Prodromou N. Supratentorial extraventricular anaplastic ependymoma in a 10 -year-old girl. Pediatric Neurosurgery 2010;46(06):480-481

4 Hamano E, et al supratentorial extraventricular anaplastic ependymoma presenting with massive calcification. Neurologia medico-chirurgica 2010;50(02):150-153

5 Akyuz C, Suna E, Akalan N, Soylemezoglu F, Kutluk T, Buyukpamukcu M. Intracranial ependymomas in childhood: a retrospective review of sixty-two children. Acta Oncologica 2000 Jan 1; 39(01):97-100

6 Kharosekar H, Bhide A, Velho V, Bijwe S, . Pediatric isolated cortical (ectopic) anaplastic ependymoma (ahead of print). asianjns.org Web site. http://www.asianjns.org/preprintarticle. asp?id=181133; type=0. Accessed April 28, 2017

7 Elsharkawy AE, Abuamona R, Bergmann M, Salem S, Gafumbegete E, Röttger E. Cortical anaplastic ependymoma with significant desmoplasia: a case report and literature review. Case Rep Oncol Med 2013;2013:1-6

8 Yadav YR, , Neha, , Chandrakar SK. Pure cortical supratentorial extraventricular ependymoma. Neurol India 2009;57:213-215 